\title{
SISTEM PEMANTAU LAMPU PENERANGAN BERBASIS JARINGAN ZIGBEE MENGGUNAKAN XBEE DAN ARDUINO
}

\author{
Totok Budioko \\ Teknik Komputer STMIK AKAKOM \\ Jalan Janti No.143, Karangjambe, Yogyakarta \\ e-mail: budioko@akakom.ac.id
}

\begin{abstract}
ABSTRAK
Lampu penerangan sangat bermanfaat di berbagai lokasi penting seperti jalan raya, daerah aliran sungai, daerah perbatasan, daerah militer, dan sebagainya, sehingga harus dipantau kondisinya setiap saat. Jika jumlah lampu yang dipantau banyak dan luasannya besar maka akan membutuhkan waktu yang panjang apabila dilakukan secara langsung. Pemantauan secara jarak jauh akan mempercepat mendapatkan informasi kondisi lampu. Dalam artikel ini dideskripsikan perancangan dan implementasi sistem pemantau lampu penerangan berbasis jaringan Zigbee menggunakan Xbee dan Arduino. Jaringan Zigbee digunakan untuk akses jarak- jauhnya dan Arduino digunakan untuk pengendalinya. Sistem ini terdiri atas Titik Sensor dan Titik Pusat Pantau. Titik Sensor mengirimkan data status lampu ke Titik Pusat Pantau menggunakan protokol Zigbee pada jaringan Zigbee. Titik Sensor diimplementasikan menggunakan Arduino, modul Xbee, sensor arus listrik, dan software dalam bahasa C/C++. Sedangkan Titik Pusat Pantau diimplementasikan menggunakan Komputer Pribadi (PC), modul Xbee dan software dalam bahasa Java. Pengujian dilakukan dengan cara menempatkan dua prototip Titik Sensor pada jarak tertentu dan memanipulasi agar lampu berubah dari kondisi nyala ke kondisi padam terus menerus secara bergantian sehingga akan terkirim status nyala dan padam secara bergantian. Teknik pengujian ini juga digunakan untuk mengukur jarak pancar Titik Sensor ke Titik Pusat Pantau. Hasil pengujian menunjukkan bahwa Titik Sensor dapat mengirimkan kondisi lampu ke Titik Pusat Pantau.
\end{abstract}

Kata Kunci: arduino, sensor arus listrik, xbee, zigbee

\begin{abstract}
Lighting lamp is very usefull for street, along river area, dangerous area, nation border area, military area, and so on. So it is must be monitored continuously. Manual monitaring is time consuming for monitoring many lamps and large areas. Remote monitoring is one solution for reduced time consumption. In this article the design and implementation of the Remote Lighting Lamp Monitoring System based on Zigbee and Arduino for node controller. This system contain two nodes; Sensor Node and Central Monitor Node. Each sensor Node transmits data lamp status to Central Monitor Node with Zigbee protocol on Zigbee Network. Sensor Node is implemented with Arduino, Xbee module, electrical current sensor, and software written in C/C++. Central Monitor Node is implemented with Personal Computer (PC), Xbee module, and software written in Java. Testing is done by placing two prototype Sensor Node at a distance and manipulation for light on and light off continuously so that light status is transmitted to the Central Monitor. This testing also to measure the distance between Sensor Node and Central Monitor. The tests indicated that Sensor Node work properly to transmits lamp conditions to Central Monitor Node.
\end{abstract}

Keywords: arduino, electrical current sensor, xbee, zigbee

\section{PENDAHULUAN}

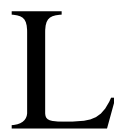

ampu penerangan sangat bermanfaat terutama pada saat hari gelap, baik karena malam, mendung, kabut tebal, asap tebal maupun hujan abu. Pada jalan raya lampu penerangan dapat meningkatkan keamanan berkendaraan baik dari tindak kejahatan maupun kecelakaan. Pada jalan khusus semisal, kompleks militer atau kompleks perusahaan, lampu penerangan dapat membantu meningkatkan keamanan wilayah dan mempermudah dalam pemantauan lingkungan.

Lampu penerangan biasanya dinyalakan dan dipadamkan secara otomatis berdasarkan sensor cahaya. Jika hari gelap secara otomatis lampu menyala dan jika hari terang lampu padam. Jika terjadi kerusakan, lampu menyala dan padam tidak sesuai dengan kondisi di atas. Kerusakan dapat terjadi pada lampu atau pada saklar otomatis lampu.

Pemantauan kerusakan dapat dilakukan secara manual dengan pengecakan lampu secara langsung atau jarakjauh. Pemantauan jarak-jauh memiliki beberapa keunggulan dibandingkan dengan pemantauan secara langsung, diantarannya adalah lebih cepat. Sistem pemantau jarak jauh dapat menggunakan media kabel, serat optik, maupun nirkabel. Sistem pemantau secara nirkabel lebih menguntungkan karena tidak memerlukan infrastruktur fisik untuk menghubungkan satu titik dengan titik yang lainnya. Ada beberapa teknologi jaringan nirkabel untuk jangkauan dekat di antaranya adalah IEEE 802.11, Bluetooth, dan Zigbee [1]. Teknologi jaringan Zigbee mempunyai keunggulan pada sisi kompleksitas yang rendah, harga lebih murah, konsumsi daya rendah, dan kecepatan transmisi mampu mencapai $250 \mathrm{Kbps}$ [1]. Kecepatan transmisi tersebut cukup untuk mengirimkan data yang perubahannya di bawah setengah dari kecepatan maksimumnya. 
Sistem pemantau kondisi lampu penerangan telah dikembangkan menggunakan beberapa metoda di antaranya, pemantauan menggunakan SMS dan Geographical Information System (GIS). Sistem ini diimplementasikan untuk lampu penerangan jalan. Informasi kondisi lampu dikirim masyarakat dan diterima oleh pusat pemantau melalui SMS Gateway. Pusat pemantau akan mengirimkan informasi ke penjaga malam atau siang dan mengirimkan balik ke masyarakat jika gangguan dapat diatasi [2]. Sistem ini masih melibatkan orang dalam memantau kondisi lampu penerang jalan.

Metode lainnya adalah dengan membuat database dan GIS (MapInfo). Data-data berkenaan dengan nomor, lokasi, jenis, tiang, kondisi, kelas jalan dari suatu lampu diambil dari lapangan dan dikelola dengan menggunakan perangkat lunak tersebut. Pemantauan dilakukan berdasarkan informasi yang telah disimpan [3]. Pemantauan pada sistem ini masih bersifat manual karena data-data tersebut masih harus didapatkan dari lapangan. Kondisi status lampu terkini tidak dapat dihasilkan secara cepat.

Artikel ini membahas hasil penelitian sistem pemantau lampu penerangan berbasis jaringan Zigbee menggunakan Xbee dan Arduino. Informasi kondisi lampu dikirim melalui jaringan Zigbee yang diimplementasikan menggunakan modul Xbee serta pengendalian pada titik sensor menggunakan modul mikrokontroler Arduino.

\section{METODE}

Penelitian diawali dengan membuat rancangan perangkat keras maupun perangkat lunak. Perangkat keras terdiri atas titik pusat pantau dan titik sensor. Diagram blok perangkat keras Sistem Pemantau Lampu Penerangan diperlihatkan pada Gambar 1.

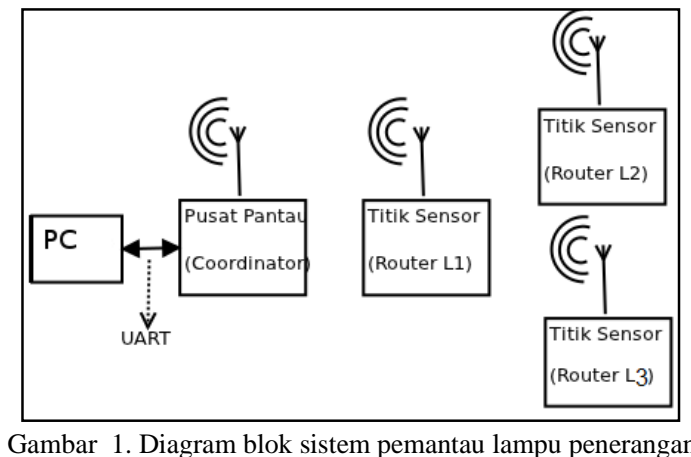

\section{A. Pusat Pantau}

Pusat Pantau terdiri atas modul Xbee, pengubah Universal Serial Bus (USB) ke Universal Asynchronous Synchronouse (UASRT) dan Komputer Pribadi (PC). PC dipakai untuk menampilkan kondisi lampu terkini yang sedang dipantau. Diagram blok Pusat Pantau diperlihatkan pada Gambar 2 [4].

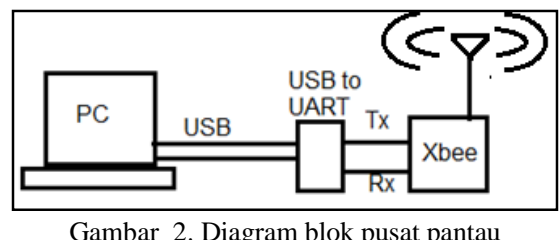

\section{B. Titik Sensor}

Titik Sensor berfungsi sebagai titik untuk mengindra kondisi lampu. Pengindraan kondisi lampu menggunakan sensor arus listrik. Jika lampu menyala maka terjadi aliran arus melalui lampu dan sensor arus sehingga kondisi lampu dapat diketahui apakah padam atau menyala. Titik Sensor terdiri atas modul Arduino, Xbee dan Sensor Arus ACS712. Diagram Blok Titik Sensor diperlihatkan pada Gambar 3.

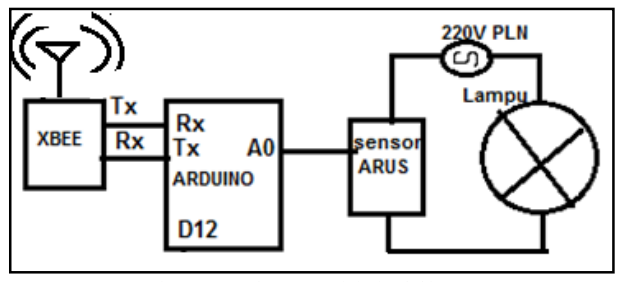

Gambar 3. Diagram blok titik sensor 


\section{Perangkat Lunak Pusat Pantau}

Perangkat lunak diimplementasikan menggunakan bahasa Java. Rancangan antarmuka pada Pusat Pantau seperti pada Gambar 4.

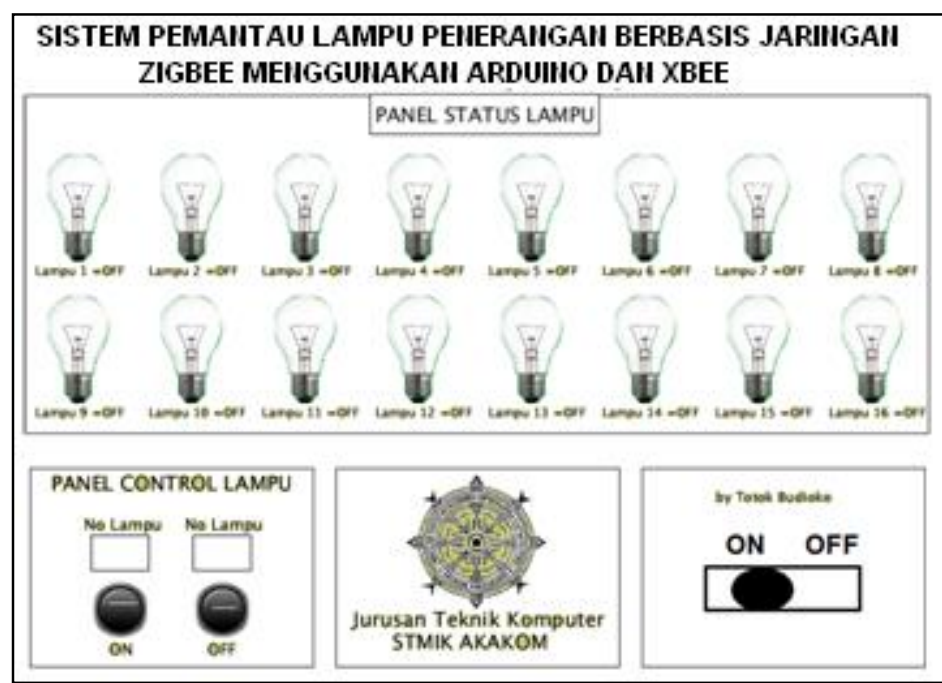

Gambar 4. Rancangan antarmuka pusat pantau

Perangkat lunak Pusat Pantau secara antarmuka terdiri atas Panel Status Lampu, Panel Control Lampu, Panel Exit aplikasi dan informasi. Algoritma Pusat Pantau terdiri atas Program Utama, Serial Event-Driven, dan Button Event-Driven dengan diagram alir diperlihatkan pada Gambar 5, Gambar 6, dan Gambar 7.
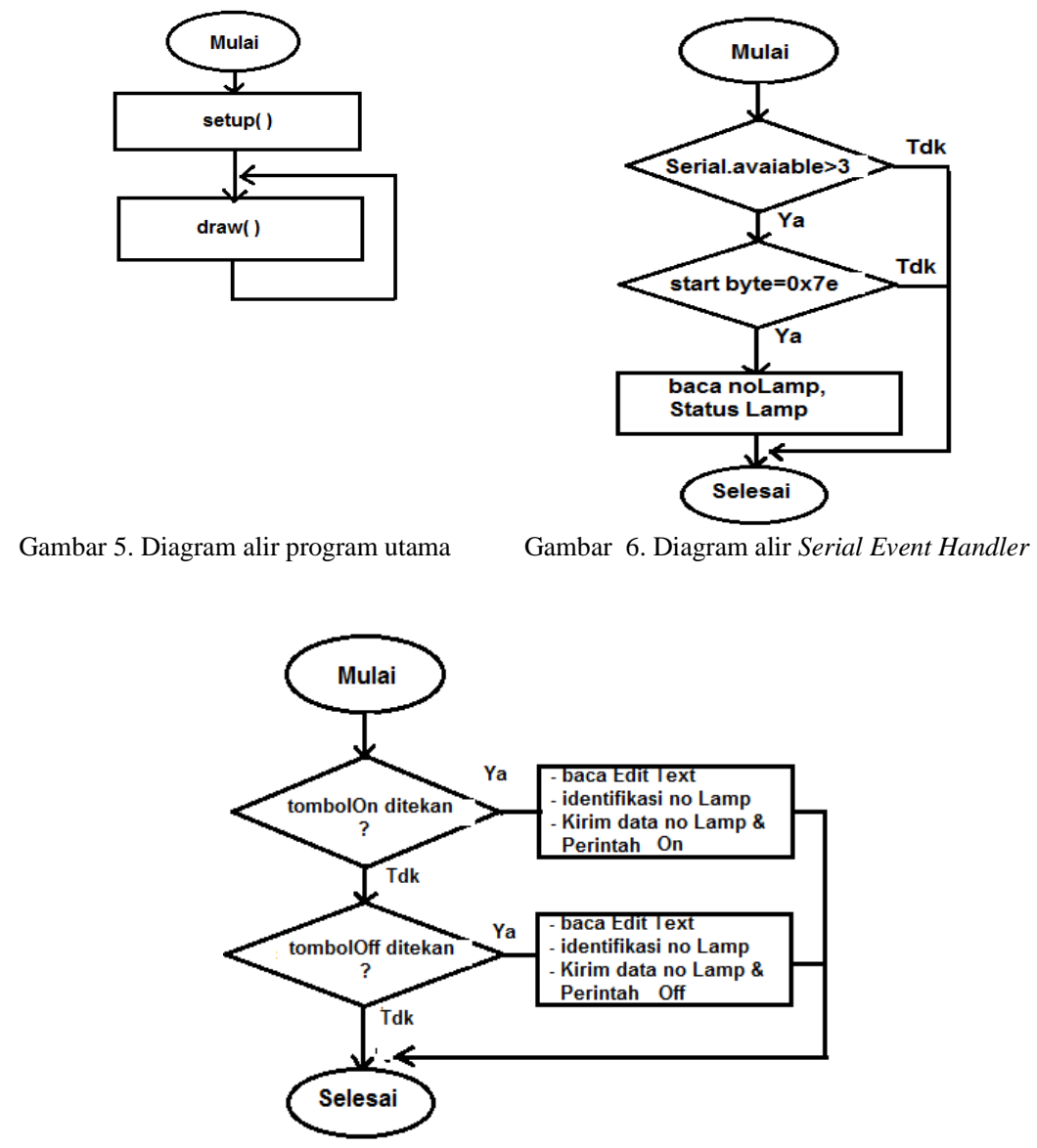

Gambar 7. Diagram alir Button Event Handler

\section{Perangkat Lunak Pusat Pantau}

Perangkat lunak pada Titik Sensor menggunakan program Arduino dengan pemrograman bahasa C/C++. Algoritma program pada Titik Sensor diperlihatkan pada Gambar 8. 


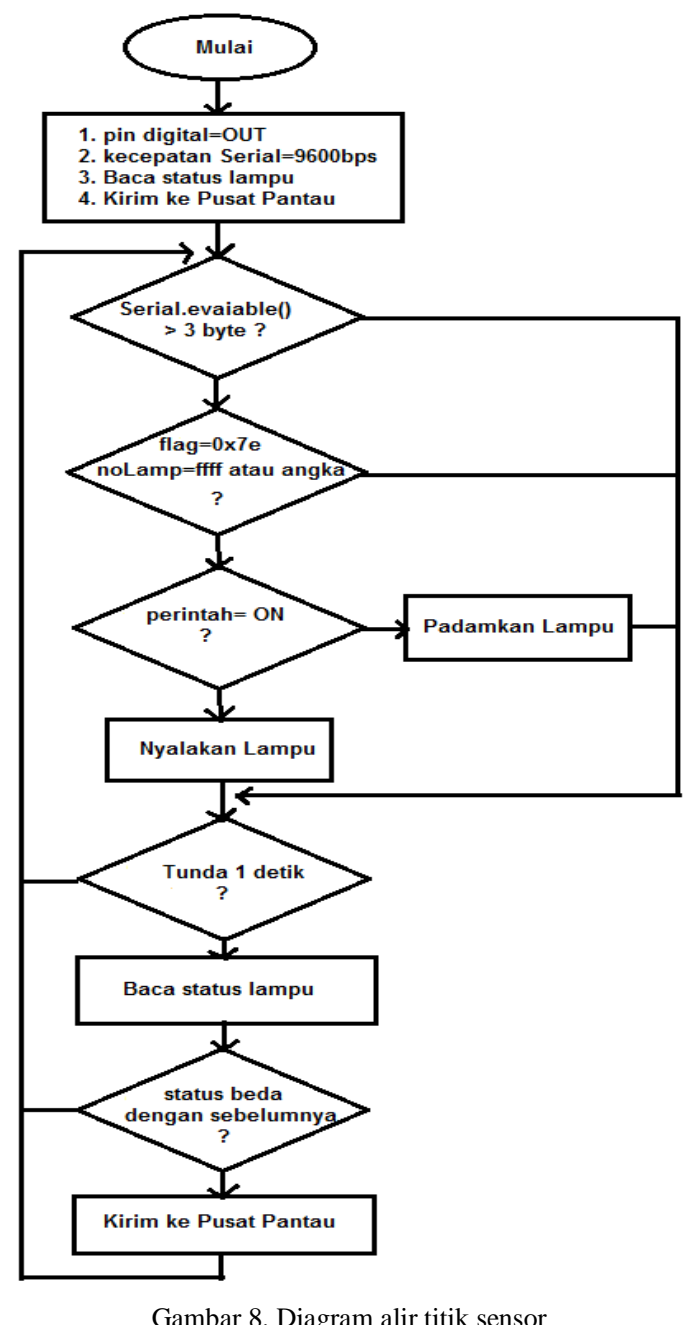

III. HASIL

Pengujian Analog to Digital Converter (ADC) dilakukan dengan cara memberikan tegangan variable DC dari 0 Volt sampai dengan 5 Volt kemudian hasilnya ditampilkan pada komputer pribadi. Pengukuran dibandingkan dengan menggunakan multimeter Heles digital. Hasil pengujian diperlihatkan pada Tabel I. Hasil pengujian ADC menunjukkan bahwa tingkat keakuratannya lebih baik dari hasil pengukuran multimeter Heles digital karena nilai terendah) Volt dan nilai tertingginya 5 Volt.

TABEL I

HASIL PENGUJIAN $A D C$

\begin{tabular}{ccc}
\hline \hline $\begin{array}{c}\text { ADC } \\
(\mathrm{dec})\end{array}$ & Multimeter (volt) & $\begin{array}{c}\text { Tegangan ADC } \\
\text { (volt) }\end{array}$ \\
\hline 0 & 0 & 0 \\
77 & 0.38 & 0.38 \\
198 & 0.98 & 0.97 \\
250 & 1.23 & 1.22 \\
512 & 2.53 & 2.50 \\
800 & 3.93 & 3.91 \\
993 & 4.88 & 4.85 \\
1093 & 5.03 & 5.00 \\
\hline \hline \multicolumn{4}{c}{} \\
HASIL PENGUJIAN ARUS LAMPU ON dan OFF \\
\hline \hline Status & 18W SL (A) & 100W Pijar (A) \\
\hline OFF & 0.01 & 0.13 \\
ON & 0.14 & 0.19 \\
\hline \hline
\end{tabular}

Pengujian yang lainnya adalah mengukur arus ketika lampu menyala dan ketika lampu padam. Pengujian dilakukan dengan cara menyalakan dan mematikan lampu menggunakan aplikasi khusus pada board ARDUINO dan menampilkan hasil pengukuran pada terminal komputer. Pengujian dilakukan menggunakan dua buah lampu 18W SL dan 100W pijar. Hasil pengujian diperlihatkan pada Tabel II. Gambar 10 memperlihatkan perangkat lunak 
pusat pantau yang dijalankan pada sistem operasi Ubuntu 14.04 LTS. Tabel III menunjukkan hasil pengujian sistem dengan berbagai ukuran jarak.

TABEL III

PENGUJIAN SISTEM

\begin{tabular}{ccc}
\hline \hline Jarak & KENDALI & Status Pusat Pantau \\
\hline $20 \mathrm{~m}$ & ON & Menyala \\
$20 \mathrm{~m}$ & OFF & Padam \\
$30 \mathrm{~m}$ & ON & Menyala \\
$30 \mathrm{~m}$ & OFF & Padam \\
\hline \hline
\end{tabular}

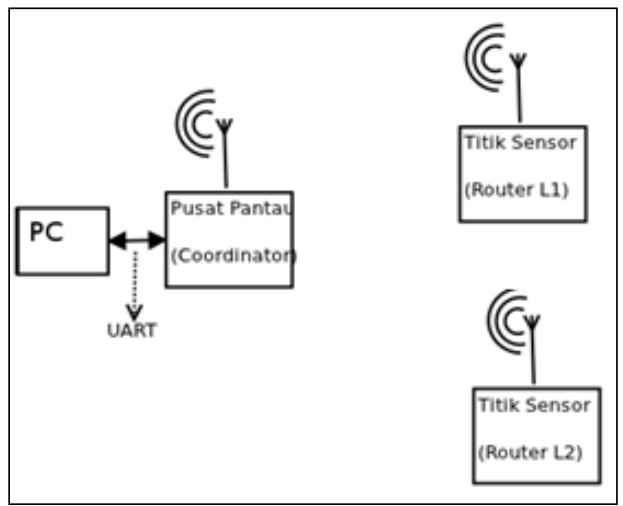

Gambar 9. Diagram blok pengujian sistem

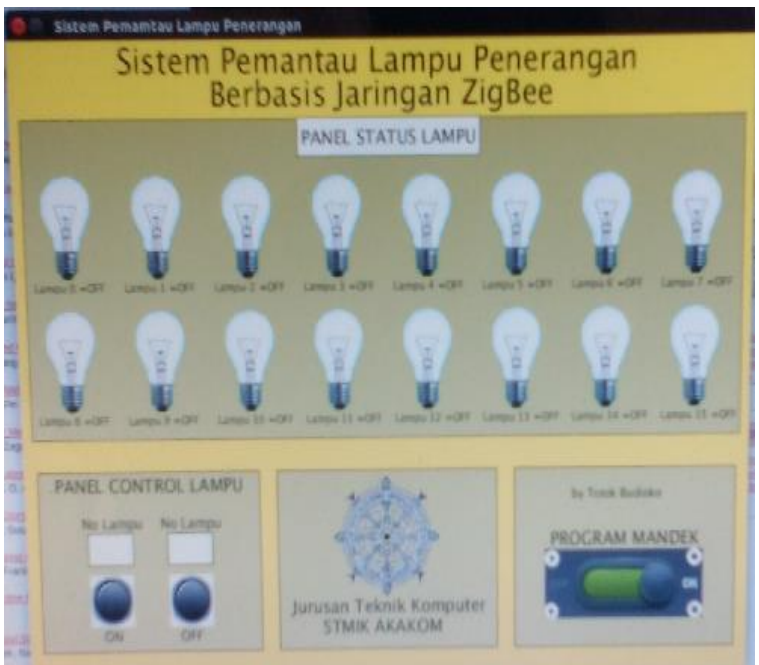

Gambar 10. Perangkat lunak pusat pantau dijalankan di sistem operasi Ubuntu 14.04 LTS

\section{PEMBAHASAN}

Terdapat perbedaan pengukuran akibat perbedaan daya lampu. Oleh karena itu perlu dilakukan pengukuran arus antara OFF dan ON untuk menentukan nilai batas pada penentuan status.

Pengujian yang lainnya adalah pengujian system secara keseluruhan yaitu dengan cara menempatkan perangkat Titik Sensor di suatu ruang dan Pusat Pantau di ruang yang berbeda. Titik Sensor sebanyak dua buah. Blok diagram pengujian sistem diperlihatkan pada Gambar 9. Hasil pengujian diperlihatkan pada Tabel III.

Berdasarkan pengujian sistem secara keseluruhan, secara prototip sistem pemantau lampu penerangan dapat berfungsi melakukan pemantauan kondisi lampu menyala atau padam. Jarak maksimal dan fungsi routing belum dilakukan pengujian.

Pada artikel [2] informasi kondisi lampu diperoleh dari masyarakat atau petugas melalui SMS yang dikirimkan kemudian sistem akan mengirimkan ke petugas lapangan. Kecepatan informasi tergantung dari informasi masyarakat sehingga wantunya tidak real time. Sedangkan pada artikel [3] hanya mengkoleksi data lampu penerang jalan yang dientrikan ke sistem peta sehingga menghasilkan data lokasi lampu pada peta. Prototip sistem pemantau lampu menghasilkan informasi yang real time namun membutuhkan Titik Sensor pada setiap lampu atau kelompok lampu sehingga membutuhkan biaya yang lebih besar. 


\section{SIMPULAN DAN SARAN}

Simpulan yang diperoleh dari penelitian ini adalah prototip sistem pemantau penerangan dapat bekerja sesuai dengan rancangan. Pantauan kondisi lampu dapat dihasilkan secara real time. Jarak maksimum antara Pusat Pantau dengan Titik Sensor belum dilakukan pengujian.

Saran yang diberikan untuk penelitian selanjutnya adalah data identifikasi lampu yang dikirim dari Titik Sensor sebaiknya berupa koordinat lokasi sehingga Pusat Pantau dapat diintegrasikan dengan sistem peta sehinga menghasilkan tampilan yang lebih baik.

\section{REFERENSI}

[1] S. Farahani, Zigbee Wireless Netwoks and Tranceivers, Elsevier Ltd, United States of America, 2008.

[2] S. Afnarius, M. Syukur, A.F. Wandra, A. F, Pembangunan Sistem Informasi Lampu Jalan Berbasiskan SMS Gateway dan GIS, Seminar Nasional Riset Teknologi Informasi (SRITI) STMIK AKAKOM Yogyakarta, 2008

[3] D. Saputra, Manajemen Data Spasial Lampu Penerangan Jalan Berbasis Geographic Information System Menggunakan Mapinfo, JURNAL MATRIX VOL. 1, NO. 2 , pp. 44-49 2011

[4] R. Faludi, Building Wireless Sensor Networks, O’Reilly Media Inc, United States of America, 2011. 